\title{
El peso del Archivo: Notables daños de no guardar a los indios sus fueros (1571) del Licenciado Polo de Ondegardo.
}

\section{The Archive's Weight: Notables daños de no guardar a los indios sus fueros (1571) by Lawyer Polo de Ondegardo.}

\begin{abstract}
Resumen
La noción de Archivo se torna central para conjeturar cómo se instaura una lógica colonial que marca y pauta los modos de apropiarse de América. El Archivo es el comienzo y el mandato (Derrida, 1997), es decir, vertebra, ordena e instituye aquello que los dioses y los hombres mandan. Impone una dinámica en la que, desde el poder, se entraman y entretejen textos que delimitan comunidades de lectores y excluyen otras. Notables daños de no guardar a los indios sus fueros (1571) del Licenciado Polo de Ondegardo, se piensa aquí atrapado en las redes del Archivo. Su manuscrito aporta a la consolidación de las políticas imperiales pautadas por Felipe II y delimita un adentro y un afuera. La naturaleza y el espacio geográfico americanos, el sistema de organización política y económica del incario, el pasado, el mito ingresan al Archivo de la mano de la escritura. Una vez allí, ella los torna objetos manipulables y los hace circular protegido por el velo del secreto. Mientras tanto, en el afuera, los cuerpos sufren la violencia de un proyecto político pacificador que culmina con el asesinato de Tupac Amaru I en la plaza pública de Lima.
\end{abstract}

Palabras claves Archivo, Polo de Ondegardo, Violencia, Andes Coloniales.

\begin{abstract}
The notion of Archive is central to know how the colonial logic marks the ways of appropriating America. The Archive is the beginning and the mandate (Derrida, 1997). It organizes, orders and institutes what the gods and men command. It imposes a dynamic in which the texts delimites a readers communities and excludes others comunities. In this articule, Notables daños de no guardar a los indios sus fueros (1571) of Polo of Ondegardo is
\end{abstract}


presented catched into the networks of the Archive. This manuscript contributes to the consolidation of imperial policies introduced by Felipe II and delimits an inside and an outside of Archive. American nature and geographic space, the political system and the economic organization of the Incas, the past, the myth, all that enters into the Archive thanks to the writing. The writing becomes them in manipulable objects and it make them circulates like a secret. Meanwhile, on the outside of Archive, the bodies suffer the violence of a pacification political project that finishes with the death of Tupac Amaru I in the public square of Lima.

Keywords Archive, Polo de Ondegard, Violence, Andean Colonial.

(El exergo) es acumular por adelantado un capital y preparar la plusvalía de un archivo. Un exergo viene a almacenar por anticipado y a pre-archivar un léxico que, a partir de entonces, debería hacer la ley y dar lalel orden. (Jacques Derrida: Mal de archivo)

Desarmo el epígrafe de Derrida (1997) para ingresar al Archivo y al universo complejo de fines del siglo XVI en los Andes Centrales. En el exergo, Derrida concentra la palabra que resuena, la que hace eco y prolonga el sonido con la finalidad de establecer e instituir un sentido o una forma. Esta convención, que consiste en el uso de una "cita con la que se encabeza un libro o documento" (RAE 2014), desde fuera del cuerpo textual lo determina y lo marca creando un campo semántico que rodea y pauta la significación. Derrida vincula ese poder del exergo con dos rasgos claves que le asigna al Archivo: el comienzo y el mandato. Rastrea en la etimología de arkhé para recordarnos que nombra dos principios fundamentales:

El principio según la naturaleza o la historia, allí donde las cosas comienzan -principio físico, histórico u ontológico- más también el principio según la ley, allí donde los hombres y los dioses mandan, allí donde se ejerce la autoridad, el orden social, en ese lugar desde el cual el orden es dado - principio nomológico. (Derrida 9) 
CATEDRAL Tomada: Revista de crítica literaria latinoamericana / Journal of Latin American Literary Criticism

El peso del Archivo: Notables daños de no guardar a los indios sus fueros (1571) del Licenciado Polo de Ondegardo.

El origen del archivo se vertebra en pos de una cita que ordena e instituye aquello que los hombres y los dioses mandan.

Prepara por adelantado, almacena por anticipado. En el juego que instaura la cita, Derrida identifica dos movimientos: el de la "elipse" y el de la "elipsis"; el primero da lugar a la curva y difiere/prolonga el sentido, el segundo hace de la omisión un aliado y esconde una forma en el círculo del secreto. Mediante estos dos gestos se conforma un pre-archivo, se acumula un capital, una plusvalía del archivo, dice Derrida. Me interesan de sobremanera estas reflexiones porque permiten pensar el peso que adquiere el Archivo en el proceso de conquista y colonización del Nuevo Mundo y conjeturar cómo se instaura ese movimiento de “elipses" y "elipsis" en la implementación de una lógica colonial que marca y pauta los modos de apropiarse de América. El texto que aquí se trabajará, Notables daños de no guardar a los indios sus fueros (1571) del Licenciado Polo de Ondegardo ${ }^{1}$, puede pensarse atrapado en las redes del exergo y del Archivo. "Citar antes de comenzar es dar el tono, dejando resonar algunas palabras cuyo sentido o forma deberían dominar la escena" (Derrida 15). En el texto de Ondegardo hay una cita que da el tono y deja entrever lo que los hombres y los dioses mandan. Concluido el 26 de junio de 1571 en el Cusco, el Licenciado lo entrega para cumplir con una Instrucción Real. La misma solicita información sobre los "Tributos en tiempos de su infidelidad (la de los indios)" (fechada en Valladolid el 20 de diciembre de 1553). La Instrucción, como el exergo, "prearchiva un léxico que, a partir de entonces, debería hacer la ley y dar la/el orden" (Derrida 15).

Marcado por el peso de un capital acumulado, el texto de Polo se entrama en el/la orden que impone la Corona Española y prolonga sus elipses al infinito. Al mismo tiempo, dibuja el círculo de la omisión y el secreto para delimitar los contornos del Archivo, de ese arcón, de ese cofre. Señala Gastón Bachelard (1965) que en el instante que un cofrecillo se abre "lo de fuera queda borrado de

1 Todas las citas pertenecen a El mundo de los incas de Polo de Ondegardo. Edición a cargo de Laura González y Alicia Alonso (1990), perteneciente a Historia 16. 
una vez y todo es novedad, sorpresa, desconocido. Lo de fuera ya no significa nada. E incluso, suprema paradoja, las dimensiones del volumen ya no tienen sentido porque acaba de abrirse otra dimensión: la dimensión de intimidad" (Bachelard 120). El entramado de textos y de curvas que entreteje la comunicación entre la Corona Española y sus funcionarios en el Nuevo Mundo demarca un adentro y un afuera del Archivo. Este intercambio comunicativo se torna correspondencia privativa que borra el afuera para potenciar la dimensión de intimidad. La naturaleza y el espacio geográfico americanos, el sistema de organización política y económica del incario, el pasado, el mito hacen su ingreso al adentro del cofrecillo de la mano de la escritura. Una vez dentro, ella los torna objetos manipulables y los hace circular protegido por el velo del secreto. Mientras tanto, en el afuera del Archivo, los cuerpos sufren la violencia de la elipsis.

Este artículo se propone dar cuenta de las operaciones que pone en funcionamiento la lógica del Archivo sobre los textos y los cuerpos. En el primer caso, parto de los lineamientos de la historia cultural de la lectura (Chartier) para indagar en un lector particular: Polo de Ondegardo como arconte e intérprete del archivo burocrático de mediados del siglo XVI andino sumergido en un circuito de lectores privativos. En el segundo caso, reflexiono sobre los modos en que esa plusvalía del archivo se articula con la violencia de las armas en el Nuevo Mundo ante la imposibilidad de dominar la vastedad de un territorio.

\section{"Mandaron responder a ella, y yo lo hice..."}

El pensador peruano Raúl Porras Barrenechea (1986) clasifica las crónicas escritas en el Perú de acuerdo a un criterio histórico-cronológico. Sitúa la producción de Polo de Ondegardo en las "Crónicas del Incario". Dentro de ellas distingue cronistas pre-toledanos, toledanos y post-toledanos. La figura del Virrey Francisco de Toledo se vuelve clave en esta clasificación porque es durante su 
CATEDRAL Tomada: Revista de crítica literaria latinoamericana / Journal of Latin American Literary Criticism

El peso del Archivo: Notables daños de no guardar a los indios sus fueros (1571) del Licenciado Polo de Ondegardo.

gobierno (1569-1581) cuando se impone la llamada Visita General y, con ella, la maquinaria burocrática prolifera aún más en documentos, instrucciones y relaciones. Es que el objetivo de la Visita en el Nuevo Mundo consiste en recabar información para la Corona. La escritura es capital porque funciona como extensión del brazo del imperio español que necesita mantener el control sobre sus colonias. Envía, entonces, visitadores, oidores, eclesiásticos, juristas para que articulen la escritura con la vista sobre el papel. De este modo se tensa el Archivo para armar una red de textos en el que "informar" y "saber" se vuelven verbos de relevancia. Garavaglia y Marchena (2005) sostienen que "el propósito de esta visita era conocer la realidad, poner remedio a la catástrofe política peruana y asegurar e incrementar las remisiones de plata" (Garavaglia y Marchena 401). María Jesús Benites (2008), por su parte, pone énfasis en la realización de una suerte de encuesta que pauta los datos a obtener: población, edades, recursos económicos, tributos pagados durante el incario, etc. Y agrega que los textos obtenidos a partir de estas encuestas constituyeron las Informaciones de Toledo, enviadas a Felipe II.

Las Informaciones encierran una gran riqueza documental y un inapreciable valor para el estudio de las genealogías incaicas y la vida cotidiana de los indígenas pero no se puede desconocer que existió un manejo tendencioso de las respuestas que justificaron el restablecimiento del tributo que se pagaba al Inca y ayudaron a demostrar el poderío reciente del incario impuesto de manera violenta. (Benites 55)

Los textos informan lo que Felipe II quiere saber. Las Informaciones de Toledo se arman para conocer y dar remedio a una zona del Nuevo Mundo que desborda al Imperio Español. Frente a la imposibilidad de dominar una geografía andina signada por el conflicto, la violencia y la enorme resistencia indígena ${ }^{2}$, una

${ }^{2}$ Con la decapitación del inca rebelde de Vilcabamba, Tupac Amaru I, en la plaza del Cuzco en 1572 y la quema de huacas efectuada por Cristóbal de Albornoz como parte de las medidas 
red textual se configura bajo los principios del comienzo y el mandato. Se da cuenta del origen y genealogía de los indios al mismo tiempo que se ordena responder a las preguntas que interesan a la Corona. Principio ontológico y principio nomológico se encuentran en la forma de la Instrucción Real, exergo, cita que da el tono, plusvalía del Archivo.

El Licenciado Polo de Ondegardo, hombre del poder ${ }^{3}$, aporta su texto a la consolidación de las políticas imperiales pautadas por Felipe II. Nos distanciamos de la clasificación de Porras Barrenechea quien lo considera un "cronista toledano" para seguir los lineamientos de Lydia Fossa (2006). Ella postula que durante el gobierno de Toledo será un informante destacado para los funcionarios recién llegados e incluso para el mismo virrey y que sus textos servirán de base para la confección de las ordenanzas de 1572 propuestas por él, pero que este aspecto no es suficiente para calificarlo de toledano. La propuesta de Fossa nos resulta oportuna porque pone el foco en la genealogía y el contexto de producción de Notables daños... para refutar la clasificación de Porras. No existe documentación que permita afirmar que el texto fue un encargo del virrey Toledo sino las solicitudes de información de la Corona que se tornan cada vez más frecuentes. Fossa, en el caso de Ondegardo, le otorga relevancia a cuatro documentos oficiales: a) la Instrucción Real sobre los tributos en tiempos de su fidelidad (20 de diciembre de 1553); b) Instrucción al virrey del Perú sobre lo de

fomentadas por el Virrey Toledo para frenar el movimiento religioso Taky Onkoy ("la enfermedad del canto"), el mundo prehispánico se somete al poder colonial ayudado por la fuerza de la ley y la violencia. La pacificación general, una de las medidas toledanas de reorganización del mundo andino, se logra a través del despliegue de instituciones de control que se ponen en funcionamiento a nivel político, religioso y económico. Éstas son necesarias para incorporar al indio a un sistema de trabajo y a una economía monetaria europeas.

${ }^{3}$ Juan Polo de Ondegardo (Valladolid, ca. 1520- La Plata, 1575), de ilustre familia de intelectuales y funcionarios de España, llega a América en 1544 (Túmbez) en la comitiva que transporta al virrey Blasco Núñez de Vela y a cargo de la comisión y salario de Hernando Pizarro para la administración de sus bienes. Como señala Raúl Porras Barrenechea (1986) fue "consejero de los virreyes y gobernadores, sus informes o memoriales a éstos sobre la condición de los indios, no son en manera alguna crónicas sino "tratados" como él mismo los llama o ensayos sobre las costumbres de los inkas" (Porras Barrenechea 179). Integra el círculo privado de Gonzalo Pizarro; luego de las contiendas entre Pizarro y La Gasca es nombrado Corregidor y Capitán General de Charca; tiene el título de Gobernador de Chuquisaca; luego el de Corregidor del Cuzco durante el mandato del Marqués de Cañete y Gobernador y Corregidor del Cuzco y Las Charcas durante la administración del Virrey Francisco de Toledo. 
CATEDRal Tomada: Revista de crítica literaria latinoamericana / Journal of Latin American Literary Criticism

El peso del Archivo: Notables daños de no guardar a los indios sus fueros (1571) del Licenciado Polo de Ondegardo.

las poblaciones y nuevos descubrimientos (de 1556); c) La Real Cédula sobre los descubrimientos de 1549 y d) Las Leyes Nuevas de 1542 con la Real Provisión de Valladolid de 1543 que las modifica. Y agrega:

Todos ellos (los documentos) se ocupan de regular el tratamiento de los nativos como vasallos contribuyentes y no como esclavos, así como los asuntos relacionados con su conservación y su evangelización, mostrando la influencia vitoriana y lascasista en la corte española. También legislan sobre la imposición de la patrilinealidad y los derechos a la herencia sobre tierras y encomendados, sobre los tributos y las medidas que deben observarse en nuevos descubrimientos. (Fossa 189)

La mirada de Lydia Fossa permite articular aún más lo que planteamos al inicio de este trabajo: pensar el peso del Archivo en el proceso de conquista y colonización del territorio. La lógica del exergo es clave para comprender Notables daños... El juego de la cita que anticipa y pre-archiva un léxico que se tornará ley/orden, se produce en el texto de Ondegardo desde el mismo momento en que se inicia la escritura: "Habiéndose tratado lo que se ha podido averiguar tocante a la religión de estos naturales, como parece por los capítulos y relaciones pasadas, que parecía que principalmente no estaba a mi cargo si no fuera negocio que en particular me fuera cometido..." (Ondegardo 35). La pluma del Licenciado se ancla en el verbo "averiguar" y en los capítulos y relaciones pasadas que han indagado sobre la religión de los naturales. Polo de Ondegardo necesita el texto previo para cumplir con el negocio que le fue cometido. El peso del verbo y el del exergo adquieren aún más fuerza a medida que el texto progresa. A tal punto que mueve la escritura (la motiva) pero también moviliza el cuerpo del Licenciado. "Movíame mucho que el conde de Nieva — visorrey que fue de estos reinos - y el comendador Briviesca de Muñatones me mostraron una instrucción de $\mathrm{Su}$ Majestad firmada de la Serenísima princesa Doña Juana; en la cual mandaba que particularmente se averiguasen en esta tierra la mayor parte de las cosas que en 
esta relación se han de tratar" (Ondegardo 37). La Instrucción Real, la escritura oficial firmada por la princesa Doña Juana, pone en marcha una empresa en la que funcionarios de la envergadura de Polo aportan el cuerpo, subordinan ojos, manos y pies al mandato imperial.

Lo tengo yo mejor entendido que los demás por haber tratado tantas veces y en tan diferentes lugares de sus negocios y pleitos, y haber errado así mismo en la determinación de ellos a los principios como los demás jueces, y haber visitado su tierra antes y después que tuviese noticia de lo ahora. (Ondegardo 36)

La Instrucción es hilo de Ariadna, el comienzo del ovillo y del Archivo ${ }^{4}$. Benites, siguiendo al Diccionario de Autoridades, la define como "documento oficial, que emitido por las autoridades influye y condiciona determinadas acciones" (Benites 145 y 146). A su vez detalla el proceso de sistematización e institucionalización que sufre este tipo textual hasta tornarse en "un sistema de verificación que pretende incorporar una mirada científica que especifique, clasifique, distinga $\mathrm{y}$ ordene los elementos naturales" (Benites 149). La Instrucción influye y pauta los textos como también los cuerpos de quienes informan. Sistematiza el ejercicio de la observación en el papel, al decir de Benites, y al mismo tiempo supone un acto de apropiación de la vista ajena por parte de la Corona para mantener el control del imperio. No es casual que el acto de mirar abra y cierre las "razones que movieron a sacar esta relación"5 y sea

${ }^{4}$ Se torna imposible pensar un inicio, un comienzo, en esta cadena de exergos que propone el Archivo. La Instrucción misma puede incluso trazar vínculos con un pre-texto: el requerimiento. Como señala Martin Lienhard (1990) este documento, de carácter autoritario, se caracteriza por no admitir, de modo alguno, réplica, ni diálogo. Al mismo tiempo, se trata de "un texto escrito legitimado a su vez por otras "escrituras"” (Lienhard 31): la jurídica y la divina. ¿Será posible hallar la punta del ovillo, el inicio de los textos que condensa el Archivo?

${ }^{5}$ El manuscrito de Polo de Ondegardo carece en sí mismo de encabezamiento. El encabezado "Notables daños de no guardar a los indios sus fueros" responde a un recorte del primer punto de la Tabla de Contenido con el que comienza el documento. La frase completa de ese primer punto es "Las razones que movieron a sacar esta relación y notable daño que resulta de no guardar a estos indios sus fueros" (BNE, Mss. 2821, ff. 1-77v). 
CATEDRAl Tomada: Revista de crítica literaria latinoamericana / Journal of Latin American Literary Criticism

El peso del Archivo: Notables daños de no guardar a los indios sus fueros (1571) del Licenciado Polo de Ondegardo.

capital en el texto íntegro. Ondegardo aduce conocer los fueros de los indios y los modos en que pagaban tributo al Inca "por la manifestación general que por sus quipos y registros hicieron ante mí, y ante los prelados de los monasterios en la ciudad del Cuzco" (Ondegardo 35 y 36). "Mirar" deviene en "fiscalizar" con el objetivo de que el quipu/registro adquiera valor de verdad. Sobre la mirada científica y legítima del funcionario y la Iglesia, el Licenciado organiza el texto en torno a presupuestos

[...] los cuales y, cada uno de ellos se ha de entender que son verdaderos, y que para su verificación ni hay ni puede haber conforme a la costumbre de estos indios más claridad de la que hallé, que no fue pequeña, pues faltándoles escrituras no pudieron tener otra que más satisfaciese a sus propios quipos por registros. (Ondegardo 39)

La claridad y la verdad de los quipus y, por ende, de la escritura, quedan supeditados al ojo de Polo. La Instrucción sistematiza la práctica de la observación e influye sobre la mano del que escribe. A su vez, el texto normativo prolonga la cadena de influencias y miradas sobre un artefacto ajeno a Occidente. El quipu ingresa a la lógica del Archivo con el aura de "claridad" y "verificación" que le otorga el Licenciado. Los ojos de Ondegardo seleccionan, recortan, ordenan los registros del incario. Rearman, en este pedido de información de la Corona, los fueros de los indios para asentar sobre ellos las prácticas evangelizadoras y colonizadoras.

\section{"Quitando lo injusto y añadiendo lo justificado..."}

El ingreso a Notables daños de no guardar a los indios sus fueros es a través de la tierra. La distribución de los tributos y los bienes fiscales es una 
preocupación que atraviesa la escritura de Polo de Ondegardo y los intereses del imperio español. "El origen de los incas"6 se asienta en el primer presupuesto:

Primeramente se ha de presuponer que el Inca de estos incas, que fueron dos parcialidades, que la una se llama Anancuzco y la otra Urincuzco, a lo que se puede averiguar porque de más no se halla memoria, eran naturales del valle del Cuzco, y aunque algunos quieren decir que vinieron de otras partes a poblar allí; pero de esto no hace mucho al caso, porque dicen que fue antes del Diluvio y traen allá ciertas imaginaciones, como cosa tan antigua no hay para que parar en ello. (Ondegardo 40)

Frente a la imaginación desmedida que Polo le asigna al relato inca, la materialidad de la tierra y sus parcialidades sostienen el presupuesto. Definido por el Diccionario de Autoridades como "lo assí assentado y hecho cierto y notorio" (Tomo V, 1737), el término "presupuesto" delimita un campo semántico en el que papel y escritura se ligan al concepto de verdad. La única verdad posible es aquella que se asienta en la escritura. El gesto del Licenciado, entonces, recupera la tierra en el texto y la separa de la imaginación. Si atendemos al párrafo antes citado, la "parcialidad" se escribe junto al presupuesto, mientras que las "imaginaciones" se colocan al final, excluidas de la lógica racional que supone "lo cierto y notorio". Los regímenes de verdad que establece Polo de Ondegardo se desprenden de un método particular de recolección de datos. En un informe anterior al que aquí trabajamos — con fecha del 12 de diciembre de 1561- y escrito a pedido del Licenciado Briviesca de Muñatones ${ }^{7}$, se lo explicita claramente:

${ }^{6}$ El texto se divide en diecinueve capítulos precedidos por una suerte de introducción. Asimismo, el manuscrito original (Mss. 2821 de la Biblioteca Nacional de España) presenta una "tabla del contenido de esta relación" que antecede a esta introducción. Allí se enlistan los capítulos (sin numeración) desde el "Origen de los incas y señores de esta tierra" hasta "Si conviene subir las tasas".

${ }^{7}$ Este informe y la cita que sigue a continuación corresponden a la edición de los textos de Polo de Ondegardo a cargo de Gonzalo Lamana Ferrario (2012). 
CATEDRal Tomada: Revista de crítica literaria latinoamericana / Journal of Latin American Literary Criticism

El peso del Archivo: Notables daños de no guardar a los indios sus fueros (1571) del Licenciado Polo de Ondegardo.

[...] me he informado de los indios viejos, que es a quien se debe dar crédito y la última diligencia que se puede hacer, por faltarles escrituras como nosotros las tenemos y las pinturas que tienen los indios de México, por las cuales todavía se saben las costumbres y señoríos con alguna más certidumbre que en este reino, en el cual casi todo lo tienen remitido a la memoria de los hombres y a lo que oyeron sus padres y abuelos. Y aunque en esto en algunas cosas modernas se puede dar algún crédito, en las antiguas es menester ayudarnos de conjeturas; y sobre todo se puede entender algo de lo que vieron los conquistadores al principio, y lo que todos entendemos de su orden que al presente tienen [...] Y habiéndose de andar al tiento yo creo que ninguno habrá trabajado en esta averiguación más que yo. (Ondegardo 143)

En este trabajo "a tientas" del jurista, toda certeza sobre el pasado se asienta en los ojos españoles. En esa lógica, las pinturas de los indios mexicanos adquieren mayor relevancia que la memoria de la voz andina porque el registro sobre un soporte similar al de la escritura genera cierto grado de fiabilidad. El testimonio de los indios viejos no se compara con el de los primeros conquistadores; sobre los segundos recae el infinitivo "entender", mientras que a los primeros sólo les cabe "informar". Si bien Ondegardo da crédito a sus informantes indígenas, "lo que vieron los conquistadores del principio" tiene más peso de verdad. El oído cae sumiso al imperio de la vista: en el acto de oír se acumulan las conjeturas; en el de mirar (tanto las pinturas mexicanas como el pasado y el presente andinos), las certidumbres.

La tierra es centro de la mirada y, en torno a ella, Ondegardo organiza sus presupuestos: 2do "[...] es que desde se determinaron (los incas) a conquistar (la tierra) y que los otros les fuesen sujetos, buscaron título y color para conseguir lo que pretendía [...]" (Ondegardo 43); 3ero "que después que se hicieron los incas señores de cada provincia, lo primero que hicieron fue reducir los indios a pueblos 
y mandarles que viviesen en comunidad [...] y que se contasen y dividiesen por parcialidades" (Ondegardo 45); 4to "que allí adonde pobló los pueblos en todo el reino en cada uno dividió las tierras en esta forma [...]" (Ondegardo 46); 5to "que ninguno (de los indios) poseyó (tierra) por merced del Inca, la cual como está dicho, tampoco dividían los herederos ni podían disponer de ella en ninguna manera" (Ondegardo 60); 6to "que ningún indio contribuyó de cosa que cogiese de la chácara o roca que le cabía para sembrar de la comunidad [...]” (Ondegardo $63)^{8}$, etc.

En este recorte que hacen los ojos de Ondegardo, la historia y origen de los incas se reduce a observar/registrar el pasado de la tierra. Los presupuestos suponen la tierra y necesitan de la genealogía del terruño que construye el jurista para satisfacer a un lector encriptado en las líneas de la escritura. Ese lector, lejos de construirse como "curioso lector"9 , se inscribe en un espacio autorizado de lectura (un circuito oficial). Ondegardo no escribe para lectores ávidos de aventuras, sino que su escritura encierra, codifica la realidad americana para un lector particular y privativo ${ }^{10}$. Si hemos definido el Archivo desde ese complejo entramado de exergos que se construyen y se organizan desde el poder, leer el

${ }^{8}$ En todos los casos las cursivas me pertenecen.

${ }^{9}$ María Jesús Benites (2012) observa cómo gravita la categoría del “curioso lector" en los textos de Gonzalo Fernández de Oviedo y Toribio de Ortiguera. Argumenta que en el caso de estos dos autores, los textos proyectan un lector oficial (el Consejo de Indias, por ejemplo) como así también un lector ajeno a la burocracia colonial: "interesado" (Oviedo) y "discreto" (Ortiguera). La presencia de este lector curioso a mediados del siglo XVI, da cuenta de la celeridad de los procesos de circulación y publicación editorial como también del acto de apropiación que implica la lectura durante la conquista y colonización del Nuevo Mundo.

10 Utilizo el término privativo como lo entiende Lydia Fossa (2006) al reflexionar sobre el intercambio de documentos confidenciales entre los miembros de la Corona española. Fossa observa que tanto las "instrucciones" como las "relaciones" se conciben dentro de un circuito de correspondencia privativo de la corte española en el que los primeros emanan del rey o de los príncipes con carácter descendente y los segundos, de funcionarios de la administración pública con carácter ascendente. "En este intercambio de misivas, el virrey o la serie sucesiva de virreyes que intervienen, funciona como un nexo que vincula a los dos polos de la comunicación: el que necesita la información (el rey) y quien la puede proporcionar (el funcionario) [...] El virrey tiene pues, la función de ente conector, relacionando estamentos superiores a Polo de Ondegardo, pero inferiores al rey, que la diplomacia cortesana no permitiría vincular" (Fossa 178). 
CATEDRAL Tomada: Revista de crítica literaria latinoamericana / Journal of Latin American Literary Criticism

El peso del Archivo: Notables daños de no guardar a los indios sus fueros (1571) del Licenciado Polo de Ondegardo.

texto del Licenciado requiere de la capacidad de penetrar en la hermenéutica del Archivo y no perderse.

Arlette Farge (1991) en la Atracción del archivo, distingue entre el texto impreso y el Archivo que atrapa. Mientras que el impreso está cargado de intencionalidad, organizado para un lector y posee una gran difusión en el público lector, el Archivo "produce una sensación de realidad [...] huella en bruto de vidas que de ningún modo pedían expresarse así, y que están obligadas a hacerlo [...]" (Farge 10). Farge hace hincapié en la fuerte carga de intencionalidad que posee el libro impreso. "Enmascarado o no, está cargado de intención; la más simple y evidente de las cuales es la de ser leído por los demás” (Farge 10). Por lo contrario, el archivo expresaría un no-dicho, "lo que nunca hubiese sido pronunciado de no haberse producido un acontecimiento social perturbador" (Farge 11). La autora subraya la presencia de un archivo que no ha sido escrito con el objeto de agradar sino para servir al poder que controla y administra justicia $^{11}$. Siguiendo estos lineamientos, es posible conjeturar que el poder y sus funcionarios son siempre autores y lectores del Archivo. Maquinaria de discursos puesta en marcha a raíz de un acontecimiento social perturbador, leer y escribir siempre evocan el gesto de servicio ante una autoridad que requiere información para vigilar y castigar. Por ende, su objetivo no es cumplir con las expectativas de un "curioso lector", sino que los textos concentran, reúnen en su interior las necesidades de un poder de turno. A los protectores del Archivo sólo les queda extender las redes, armar el círculo y encerrar en su interior a un grupo reducido de lectores ${ }^{12}$.

${ }^{11}$ Cabe aclarar que el archivo sobre el que trabaja Arlette Farge es el Archivo judicial parisino del siglo XVIII, reunido en series en el Archivo Nacional, en la Biblioteca del Arsenal y en la Biblioteca Nacional. Retomo algunas de sus reflexiones porque resultan pertinentes para pensar los textos escritos en la segunda mitad del siglo XVI andino y en particular aquellos vinculados a la Visita General de Francisco de Toledo.

${ }^{12}$ Parto de una categoría de lector como constructor de sentido, tal como la complejiza por Roger Chartier (2005). El francés pone el foco en las prácticas lectoras como construcciones ancladas en procesos históricamente determinados y que varían en cuanto a tiempos, lugares y comunidades. En ese sentido sostiene que la lectura está siempre encarnada en gestos, espacios y costumbres; por lo que una historia de las formas de leer "debe identificar las disposiciones específicas que distinguen las comunidades de lectores y las tradiciones de lectura. Esta 
La relación de Polo de Ondegardo continúa esta lógica. Se trata de un texto que proyecta un lector inserto en el círculo de las confidencialidades. Si, como señala Roberto González Echevarría (1998), “en el siglo XVI, escribir estaba subordinado a la Ley" (González Echevarría 77) dicha sujeción de la escritura implica que la lectura también se vea redefinida y mediada por el sistema jurídico. En otras palabras, necesita de un lector competente capaz de poner en práctica, en el ejercicio de la lectura, los códigos de la Ley. Polo de Ondegardo, por lo tanto, escribe ajustado a una casuística jurídica y teológica inmutables y el lector del texto debe estar inmerso en ellas para comprenderlo. El círculo de la confidencialidad se cierra aún más y requiere tanto del secreto como del saber. El ingreso a un texto del Archivo se logra adquiriendo "el derecho y la competencias hermenéuticos" (Derrida 11). Los arcontes tienen el poder de interpretar los archivos. El Licenciado hace relación pero quien lo lee debe ser competente en el arte de la consignación para descifrar el código. Para Derrida uno de los poderes arcónticos es el poder de consignación, entendiendo el término como el acto de consignar reuniendo los signos. "La consignación tiende a coordinar un solo corpus en un sistema o una sincronía en la que todos los elementos articulan la unidad de una configuración ideal” (Derrida 11). El lector del Archivo, entonces, dispone los signos, los reúne y los articula en una unidad interpretativa. El arte de leer a Polo de Ondegardo consiste en sumergirse en los múltiples exergos que gravitan hasta el hartazgo en la profundidad del texto. Rascar la superficie textual para descubrir esa sincronía o configuración ideal que sostiene el acto de escribir. Sólo así el lector podrá penetrar en el centro, detentar el poder de consignación.

[...] por que esta regla que en todo lo que se hubiere de ordenar conviene a saber la costumbre de estos naturales $\mathrm{y}$ orden que tuvieron para sustentarse y poblarse, y para su conservación como lo hallamos y

afirmación supone el reconocimiento de muchas series de contrastes" (Chartier 51) como así también comprender que ese lector de apodera de los bienes simbólicos de una comunidad y un tiempo específicos produciendo usos y significaciones diferenciadas. 
CATEDRAL TOMADA: Revista de crítica literaria latinoamericana / Journal of Latin American Literary Criticism

El peso del Archivo: Notables daños de no guardar a los indios sus fueros (1571) del Licenciado Polo de Ondegardo.

arrimándonos a aquello ordenar lo que sobre ello pareciere, quitando lo injusto y añadiendo lo justificado, siempre se hallará provechosa, porque cualquiera que tomare otro camino creyendo ponerles nueva orden, aprisa, quitándoles la suya, saldrá con dejarles sin ninguna, y que ellos ni él no se entiendan y no conseguirá otro efecto. (Ondegardo 70 y 71)

Si la tierra ocupa y preocupa a Polo y sus lectores, poseerla definitivamente implica una justificación jurídica, teológica y ontológica que sustente la anexión. Mientras Polo contrapone la materialidad del terruño a las imaginaciones sin freno de los indios, la Corona y sus funcionarios imaginan/traman un respaldo legal que les permita legitimar la colonización del espacio andino. El lector se topa con una genealogía de la tierra armada por los ojos del Licenciado, pero tras de ella, quien lee descubre los trozos del manuscrito de Francisco de Vitoria y la Escuela de Salamanca tramando las justificaciones para la posesión de un territorio. El exergo y sus elipses vuelven a reaparecer con la fuerza de un tifón. Se lee el Archivo con múltiples voces resonando en el oído. El gesto de "quitar lo injusto añadiendo lo justificado" tiene su eco en la Relectio de Indis (1537) de Vitoria. Treinta y cuatro años antes del texto de Ondegardo, el teólogo Vitoria reconoce el dominio de los indios sobre sus propias tierras con un claro objetivo estratégico: justificar una guerra justa. Respecto a los pueblos bárbaros sostiene:

Y así, aún supuesto que estos bárbaros sean tan ineptos y romos como se dice, no por eso debe negárseles el tener verdadero dominio, ni tenérseles en el número de los siervos civiles. Verdad es, no obstante, que de esta razón y título puede nacer algún derecho para someterlos. (Vitoria 36) 
Estructurada en diecisiete títulos organizados según lo positivo y lo negativo del mundo indio, el teólogo de la Universidad de Salamanca ${ }^{13}$ anota en su Relectio de Indis: "Por lo que creo que el que (los indios) nos parezcan tan idiotas y romos (insensati et habetes) proviene en su mayor parte de la mala y bárbara educación” (Vitoria 36). Vitoria construye al indio desde la imagen del niño que necesita del tutelaje del adulto para alcanzar la ley natural. Dice Anthony Pagden (1988) al respecto: “Como los niños de otras razas, un día se convertirá en un ciudadano libre e independiente de una pólis verdadera. Pero hasta que llegue ese momento, debe permanecer por su propio bien bajo la tutela justa del rey de España” (Pagden 148). Ondegardo refuerza este axioma y sostiene:

Que aunque para hacerlos cristianos está sabido el camino y tenemos por maestro a la misma sabiduría, es necesario saber sus opiniones y costumbres para quitárselas, predicándoles primero contra ellas, y ayudarnos de aquello que por ley natural ellos hubieren alcanzado, porque tenga fundamento lo que se hiciere y con menos trabajo vengan en conocimiento de la verdad. (Ondegardo 71)

Quitar lo injusto para añadir lo justificado supone un reconocimiento del derecho del "otro" para someterlo. Tomar el camino de la imposición aprisa, sólo genera un abismo entre "naturales" y "españoles". Francisco de Vitoria postula tres reglas o cánones para hacer la guerra. La tercera expresa que "el vencedor se considere como juez entre dos repúblicas [...] para que de esta manera profiera su sentencia no como acusador, sino como juez, con la cual pueda satisfacer a la

13 Anthony Pagden (1988) establece como importante dentro de la historia de la vida intelectual española — entre los años 1520 y 1530 — la presencia de la Escuela de Salamanca. Sostiene que genera un movimiento renovador dentro de la teología, la lógica y el derecho. Entre sus miembros destaca la generación de los dominicos Francisco de Vitoria (c. 1492-1546), Domingo de Soto (1494-1560) y Melchor Cano (1509-1560) hasta los jesuitas Francisco Suárez (15481617) y Luis de Melina (1533-1600). Por otro lado, destaca el impacto de Relectio de Indis en el seno de la vida académica y teológica del siglo XVI. Se trata de "una obra que aunque no se imprimió hasta 1557, siete años después de la muerte del autor, circuló ampliamente como manuscrito antes de esa fecha tanto dentro como fuera de la Universidad de Salamanca y tuvo un impacto duradero en las discusiones posteriores sobre las cosas de Indias" (Pagden 99). 
CATEDRal Tomada: Revista de crítica literaria latinoamericana / Journal of Latin American Literary Criticism

El peso del Archivo: Notables daños de no guardar a los indios sus fueros (1571) del Licenciado Polo de Ondegardo.

nación ofendida" (Vitoria 101). La figura del juez potencia aún más la necesidad de arrimarse a las costumbres de los indios propuesta por Ondegardo. Relectio de Indis puede leerse como un tratado de tácticas para anexar territorios que tiene su correlato en el intercambio privativo de documentos confidenciales articulado por la Corona. Además, el juez pone en el rol de proveedor al vencedor: satisface las necesidades de la nación subordinada e infantiliza al bárbaro. El lugar de tutor es el de quien está más cerca de la verdad y, por ende, legitimado para acercarla. Ondegardo deja escapar esta expresión casi al final del texto: "porque aún son tiernos y nuevamente reducidos y la verdadera libertad es que vivan como a ellos propios les conviene, como niños, hasta que el tiempo muestre que tienen capacidad para tratarlos de otra manera" (Ondegardo 165).

A su vez, en el manuscrito de Ondegardo palpitan las disposiciones de Juan Ovando y Godoy publicadas el 24 de septiembre de 1571. Las Ordenanzas Reales del Consejo de Indias son materialización de las reformas que lleva adelante Ovando en el Consejo de Indias a partir de la información obtenida por los funcionarios administrativos desplegados en el Nuevo Mundo ${ }^{14}$. Es interesante observar cómo estas nuevas Ordenanzas deponen el término "conquista" por el de “pacificación”. Esta alteración supone un cambio en los criterios de apropiación del continente.

Los nuevos criterios para obtener la pacificación procedían en este orden: asentamiento de la población española; entrada en contacto pacífico con los indios solicitando la sumisión al emperador y aceptación de la fe; establecimiento de rescates o trueque de mercancías; explicación del poder del monarca y su genuina finalidad. (Fernández-Largo100)

\footnotetext{
${ }^{14}$ Para Antonio Osuna Fernández-Largo (1991), entre 1566 y 1596 "la legislación indiana obtuvo gran autonomía de contenidos frente a la legislación castellana por sus propias fuentes jurisdiccionales y gubernativas, iniciándose así la realidad de un derecho indiano" (FernándezLargo 97).
} 
En este contexto, no debería llamarnos la atención, entonces, que Polo insista en su texto en construir a los reyes incas como conquistadores y tiranos: "El segundo presupuesto es que desde que se determinaron a conquistar y que los otros les fuesen sujetos, buscaron título y color para conseguir lo que pretendían, que es cosa natural" (Ondgardo 43). El mito de origen se reduce no sólo a imaginación sino a un artilugio político e imperial en el que la pretensión de sujeción de los incas respecto a otros pueblos "era y fue importantísima" (Ondegardo 46). Al colocar la "conquista" en los Incas, la "pacificación" involucra las instituciones religiosas del lado de los españoles. A la insistencia por la tiranía incaica, le sigue la del Real Patronazgo. Ondegardo no quiere tratar la conversión en el texto ("Lo primero trataremos de la conversión brevemente, aunque no sea este su lugar" Ondegardo 72) pero le dedica un importante fragmento en su exposición. Pacificar, además de responder a una lógica de la guerra, remite a una lógica eclesiástica clave para la obtención del control de la tierra, los cuerpos y las almas.

En esta cadena de exergos, la práctica de la lectura se encuentra mediada por textos previos que deben conocerse. "Saber" como operatoria para colonizar un territorio, pero también como sentido de pertenencia, llave maestra que abre el ingreso al país de los doctos. Para Michel de Certeau (1997) "la autonomía del lector depende de una transformación de las relaciones sociales que sobredeterminan su relación con los textos" (Michel de Certeau 185). Desde esta perspectiva, las relaciones sociales de una comunidad son claves para comprender los modos en que el lector se vincula con el texto. Indudablemente, la comunidad lectora que se arma tras el manuscrito de Ondegardo responde al modelo político de la Burocracia Patrimonial ${ }^{15}$ sobre la que se asienta América en el siglo XVI, es

15 Para Roberto González Echevarría (1998) América está asentada sobre una Burocracia Patrimonial en el siglo XVI. El autor destaca que dicha Burocracia nace de una dualidad en el sistema político español, heredera de la Escolástica: mezcla entre Estado Patrimonial y Estado Burocrático. Por un lado, el Estado Patrimonial implica un señorío basado en la tierra en la que media una extensión de los lazos patrimoniales que vincula al señor con su linaje, sus criados y siervos. El poder se legitima a través de la tradición. Por otro lado, el Estado Burocrático se organiza en una racionalidad funcional del sistema. Sus funcionarios se eligen conforme a su capacidad y funciona como una maquinaria cerrada que se regula a sí misma. 
CATEDRAL TOMADA: Revista de crítica literaria latinoamericana / Journal of Latin American Literary Criticism

El peso del Archivo: Notables daños de no guardar a los indios sus fueros (1571) del Licenciado Polo de Ondegardo.

decir, reproduce los lazos patriarcales/asimétricos entre el rey y sus funcionarios. La maquinaria cerrada y funcionalista de la burocracia imperial opera anulando la autonomía del "curioso lector". En este circuito de lectores-arcontes, se lee y se escribe para y con la Ley porque desde ella se leg-itiman pre-textos, exergos y lecturas autorizadas que hacen de la práctica lectora un coto de caza reservado. "La creatividad del lector crece a medida que decrece la institución que la controlaba" (Michel de Certeau 185). El Archivo de mediados de siglo XVI en el Nuevo Mundo amplía sus elipses y elipsis. Si todo lector es un viajero, cazador nómada furtivo sin lugar fijo, el lector inserto en la maquinaria administrativa del imperio español tiene frente a sus ojos el imponente Archivo, lugar por antonomasia que lo torna un sedentario empedernido y le anula la creatividad ${ }^{16}$.

\section{"Y de esto sucede entenderse y aún sentenciarse mal los pleitos..."}

La violencia del archivo. La violencia archivadora. Derrida (1997) postula un doble movimiento del Archivo: es al mismo tiempo instituyente y conservador; revolucionario y tradicional.

Archivo eco-nómico en este doble sentido: guarda, pone en reserva, ahorra, mas de un modo no natural, es decir, haciendo la ley (nomos) o haciendo respetar la ley [...] Tiene fuerza de ley, de una ley que es la de la casa (oikos), de la casa como lugar, domicilio, familia, linaje o institución. (Derrida 15)

El peso del Archivo se torna violencia en el gesto de hacer respetar la fuerza de la ley de un ausente. Violencia achivadora que durante el gobierno del

16 Lejos de hacer un plateo reduccionista de las prácticas lectoras, el propósito del artículo es iluminar un circuito de lectores en particular y observar cómo construyen significados y se apropian de los textos. Esto no equivale a sostener el completo desconocimiento de esos otros lectores, sino más bien a un recorte a los fines de esta propuesta. 
virrey Francisco de Toledo se traduce en un programa de pacificación que culmina con el asesinato de Tupac Amaru I en la plaza pública. Los textos del Archivo organizan los argumentos jurídico-teológicos de dominación del espacio andino pero el cúmulo de papeles, de textos y pre-textos se torna obsoleto frente a la violencia que instauran las armas sobre el cuerpo de los indios. Si, como señala González Echevarría (1998), en el Nuevo Mundo la autoridad paterna (del rey) se vuelve cada vez más una entelequia que no imparte justicia sino mediada por la estructura interna y sistémica de la burocracia, la escritura se torna fundamental para poder comunicarse con el padre ausente que gobierna desde la distancia.

La relación de Ondegardo evidencia y da cuenta de la contradicción entre el papel y las armas. La propuesta de Polo se estructura en presupuestos con valor de verdad pero también intenta brindar soluciones a los pleitos y conflictos que suscitan los indios. El texto adopta un objetivo utilitario: brindar asesoramiento a los jueces y funcionarios que lidian con multitudinarios pleitos. Notables daños... puede pensarse como un escrito que otorga "remedios" (vocablo que vuelve una y otra vez a la boca de Polo) a los conflictivos litigios que sostiene la Corona contra los indios. El botín o motivo de conflicto es siempre la tierra, eje axial de la relación. El Licenciado remarca los errores cometidos por la administración española en Indias y brinda su saber experto al rey a modo de servicio. La argumentación de Ondegardo redunda y reitera que las tierras son comunitarias y todas dependientes del poder del Inca para que por transitividad sean anexadas por Felipe II

Pero si alguno (algún indio) quisiere hacer fundamento como le hacen en decir que el Inca las pudo aplicar para sí (a las tierras), por esa misma razón es mayor el agravio e injusticia, porque si el derecho realengo sucede en él Su Majestad y estas encomiendas que hace temporales por vida o vidas como a él le parece, claro está que no es su intento, ni es justo que lo sea en encomendar la hacienda de los indios, sino lo que a él le pertenece. (Ondegardo 50 y 51) 
CATEDRal Tomada: Revista de crítica literaria latinoamericana / Journal of Latin American Literary Criticism

El peso del Archivo: Notables daños de no guardar a los indios sus fueros (1571) del Licenciado Polo de Ondegardo.

El derecho realengo y de sucesión del poder le sirve a Ondegardo para darle derechos a Su Majestad sobre las tierras del Perú. Polo llama a este hecho "comprender el negocio", comprender la jurisprudencia de los naturales para apropiarse de sus tierras. Sin embargo, frente a la lógica argumental que estructura el Licenciado amparado desde la jurisprudencia y construida bajo la sombra del Archivo, la Relación del experto en leyes necesita, requiere del cuerpo del indio para cerrar la argumentación y clausurar la propuesta:

[...] la justicia es que cada uno se quede en sus tierras y las siembre para sí $[\ldots]$ y que pues los del inca y del sol eran de los indios, que esto no hay para que poner en duda, sea de la comunidad de cada república y ellos paguen su tributo como está tasado. (Ondegardo 68)

Comprender el "negocio" supone la inmovilidad del indio en la tierra para que funcione efectivamente el sistema tributario. Dicha inmovilidad hace del Archivo un aliado absoluto. Violencia archivadora que penetra e inscribe su ley/orden en los cuerpos de los indios. Anclarlos a la tierra supone la presencia de la Iglesia, la conversión y el Patronazgo. Ondegardo explicita ese remedio apelando a la comparación bíblica del pastor y sus ovejas, y una metáfora recurrente: la del remedio y la enfermedad.

[...] de manera que el principio y fundamento del negocio ha sido que el pastor conozca a sus ovejas y ellas a él, para que sepa la enfermedad de cada una, y esta orden suya antigua que es no mudarse cada uno de su pueblo, ayuda para esto maravillosamente y es fácil de conservar porque es propia, con el cual el miedo y las visitas, y continuación de averiguar lo que sobre todo pasa con algún castigo cuando alguno excede, los refrena y escarmienta para que vivan menos mal que solía. (Ondegardo 73) 
Si Polo de Ondegardo se desplaza geográficamente, se mueve para dar cuenta de la administración del incario, los indios deben permanecer como cuerpos momificados. De lo contrario, un castigo los refrenará y les servirá de escarmiento. La inmovilidad del indio debe concretarse para someterlo al control y, al mismo tiempo, fijar sus cuerpos en el libro de las Visitas. Vuelve y resuena como un exergo la voz de Derrida: el Archivo es al mismo tiempo instituyente y conservador. Nada más cercano al peso de la institución que la fuerza del castigo para paralizar una vida. Nada más cercano al afán de conservar que las momias apiladas como papeles, textos y pretextos.

El acto de inmovilizar, fijar o anclar, propuesta por el Licenciado Polo de Ondegardo, tiene su contraparte en una escena que lo fijará en los memoriales del Perú para siempre ${ }^{17}$ : el mismo Ondegardo develando tumbas y hallando momias de reyes. El Licenciado las descubre en el Cuzco y luego las envía a Lima por orden del Marqués de Cañete. El perfil de Polo se agiganta con el hallazgo de los cuerpos de Pachacutec Inca Yupanqui, Huayna Capac y la Colla Mama Ocllo. Las momias se exhiben como trofeos en el Hospital de San Andrés de Lima. Esta escena vuelve a conjugar el verbo saber y lo lleva a su límite más horroroso. Se han profanado las tumbas y el cuerpo inmóvil, yacente es futo de espectáculo. El Archivo ha impuesto su peso; sus elipses han tramado hasta llegar a ultratumba. Ha anulado al curioso lector y su creatividad. Ahora se ha posado sobre los cuerpos.

\section{A modo de cierre}

Gonzalo Lamana Ferrario (2012) conjetura que los textos de Polo de Ondegardo articulan un doble movimiento: por un lado, explicitan el fracaso del

17 Es insoslayable, en este sentido, el encuentro que describe El Inca Garcilaso de la Vega con Polo de Ondegardo en los Comentarios Reales. Allí el autor detalla la sorpresa que siente al visitar la casa del Licenciado y encontrarse con las momias de sus antepasados conservadas en el tiempo. 
CATEDRAL Tomada: Revista de crítica literaria latinoamericana / Journal of Latin American Literary Criticism

El peso del Archivo: Notables daños de no guardar a los indios sus fueros (1571) del Licenciado Polo de Ondegardo.

colonialismo español en los Andes; por otro, ofrecen un "remedio" a ese fracaso, pero justificando la continuidad de la matriz colonial en el territorio. En ese sentido, la escritura del Licenciado es deudora de su contexto: el impase entre el proto-orden colonial temprano y el colonialismo maduro que implantarían las reformas toledanas.

El recorrido por estas páginas propuso una serie de lineamientos para seguir pensando ese doble gesto escriturario de Ondegardo. Notables daños de no guardar a los indios sus fueros se aferra a la lógica del Archivo y desde allí continúa perpetuando el sistema de dominación colonial. Su peso dibuja un círculo de confidencialidad en el que el origen, el pasado, el mito, el sistema tributario, la tierra del incario ingresan a la cadena de exergos del Imperio Español para que los lectores-arcontes se apropien de ellos. En esa apropiación, el proyecto político de Polo intenta ofrecer una solución explicitando los daños que supone no mantener vigente el orden incaico. Sin embargo, esa visibilización de errores no se desvincula de la maquinaria burocrática colonial, sino que "da el tono" a los modos de dominar y representar el territorio andino. Una "taxidermia"18 se apodera del discurso y de los cuerpos: los sentidos se fijan dentro de la comunidad lectora del Archivo; el control embalsama los cuerpos indígenas.

\footnotetext{
${ }^{18}$ Dialogo aquí con la lectura de Gonzalo Lamana Ferrario (2012) quien sostiene que el proyecto político de Polo de Ondegardo es la taxidermia: "los indios no sólo tienen que permanecer sin cambios, sino que tienen que ser forzados a ser del modo en que (supuestamente) habían sido [...] El principio general es forzar a los indios porque a ellos (españoles) les conviene, lo cual será la marca registrada del proyecto toledano" (62).
} 
CATEDRAL TomadA: Revista literaria latinoamericana / Journal of Latin American Literary Criticism Oscar Martin Aguierrez

\section{Bibliografía}

Ondegardo, Juan Polo de. Relación histórica acerca de los Incas y del Cuzco [1571]. Mss. 2821. Biblioteca Nacional de España. Texto digitalizado y disponible en http://www.bne.es/es/Catalogos/BibliotecaDigitalHispanica/Inicio/index.ht $\mathrm{ml}$

Ondegardo, Polo de. El mundo de los incas [1571]. Laura González y Alicia Alonso editoras. Madrid: Historia 16, 1990.

Ondegardo, Polo. Pensamiento colonial crítico. Textos y actos de Polo Ondegardo. Edición de Gonzalo Lamana Ferrario. Cusco: Centro de Estudios Regionales Andinos Bartolomé de Las Casas, IFEA, 2012

\section{Bibliografía crítica}

Bachelard, Gastón. La poética del espacio. México: Fondo de Cultura Económica, 1965.

Benites, María Jesús. Con la lanza y con la pluma. La escritura de Pedro Sarmiento de Gamboa. San Miguel de Tucumán: Instituto Interdisciplinario de Estudios Latinoamericanos (IIELA). Facultad de Filosofía y Letras. Universidad Nacional de Tucumán, 2008

Benites, María Jesús. "A quien quisiere saber... La construcción del "curioso lector” en los relatos de viajes del siglo XVI”. Crítica Cl. XV (2012): 1-6.

Certeau, Michel de. La invención de lo cotidiano. 1. Artes de hacer. México: Universidad Iberoamericana. Instituto Tecnológico y de Estudios Superiores de Occidente, 1997.

Chartier, Roger. El mundo como representación. Estudios sobre historia cultural. Barcelona: Gedisa, 2005.

Derrida, Jacques. Mal de archivo. Una impresión freudiana. Madrid: Trotta, 1997.

Diccionario de Autoridades (1726-1739). Edición on line. www.rae.es

Diccionario de la Real Academia Española (2014). Edición on line. www.rae.es

Farge, Arlette. La atracción del archivo. Valencia: Alfons El Magnánim Institució Valenciana D'estudis i Investigació, 1991.

Fernández-Largo, Antonio Osuna. "Ética y política en las Leyes de Indias del siglo XVI”. Anuario de Filosofía del Derecho. VIII (1991): 77-102.

Fossa, Lydia. Narrativas problemáticas: los inkas bajo la pluma española. Lima: Pontificia Universidad Católica del Perú - Instituto de Estudios Peruanos, 2006.

Garavaglia y Marchena. América Latina. De los orígenes a la independencia. Vol. 1. Barcelona: Crítica, 2005.

González Echevarría, Roberto. Mito y Archivo. Una teoría de la narrativa latinoamericana. México D.F.: Fondo de Cultura Económica, 1998. 
CATEDRAL Tomada: Revista de crítica literaria latinoamericana / Journal of Latin American Literary Criticism

El peso del Archivo: Notables daños de no guardar a los indios sus fueros (1571) del Licenciado Polo de Ondegardo.

Inca Garcilaso de la Vega. Comentarios Reales de los Incas [1609]. Buenos Aires: Emecé, 1943

Lamana Ferrario, Gonzalo. "Pensamiento colonial crítico. Polo Ondegardo, los Andes y los estudios andinos". Pensamiento colonial crítico. Textos y actos de Polo Ondegardo. Cusco: Centro de Estudios Regionales Andinos Bartolomé de Las Casas, IFEA, 2012.

Lienhard, Martin. La voz y su huella: Estructura y conflicto etnico-social en America Latina (1492-1988). La Habana: Casa de las Americas, 1990.

Pagden, Anthony. La caída del hombre natural: el indio americano y los orígenes de la etnología comparativa. Madrid: Alianza, 1988.

Porras Barrenechea, Raúl. Los cronistas del Perú (1528-1560). Biblioteca Peruana, Banco de Crédito del Perú, 1986.

Vitoria, Francisco de. Relecciones del estado, de los indios y del derecho de la guerra [1537]. México: Editorial Porrúa, 1985. 